\title{
Biotransformation Changes Bioaccumulation and Toxicity of Diclofenac in Aquatic Organisms
}

\author{
Qiuguo Fu, ${ }^{*}$ Davide Fedrizzi, Verena Kosfeld, Christian Schlechtriem, Vera Ganz, Samuel Derrer, \\ Daniel Rentsch, and Juliane Hollender*
}

Cite This: Environ. Sci. Technol. 2020, 54, 4400-4408

Read Online

\section{ACCESS |}

Џlll Metrics \& More

Article Recommendations

Supporting Information

ABSTRACT: Biotransformation plays a crucial role in regulating the bioaccumulation potential and toxicity of organic compounds in organisms but is, in general, poorly understood for emerging contaminants. Here, we have used diclofenac as a model compound to study the impact of biotransformation on the bioaccumulation potential and toxicity in two keystone aquatic invertebrates: Gammarus pulex and Hyalella azteca. In both species, diclofenac was transformed into several oxidation products and conjugates, including two novel products, that is, diclofenac taurine conjugate (DCF-M403) and unexpected diclofenac methyl ester (DCF-M310.03). The ratios of biotransformation products to parent compound were 12-17 for DCF-M403 and 0.01-0.7 for DCF-M310.03 after $24 \mathrm{~h}$ exposure. Bioconcentration factors (BCFs) of diclofenac were 0.5 and $3.2 \mathrm{~L}$

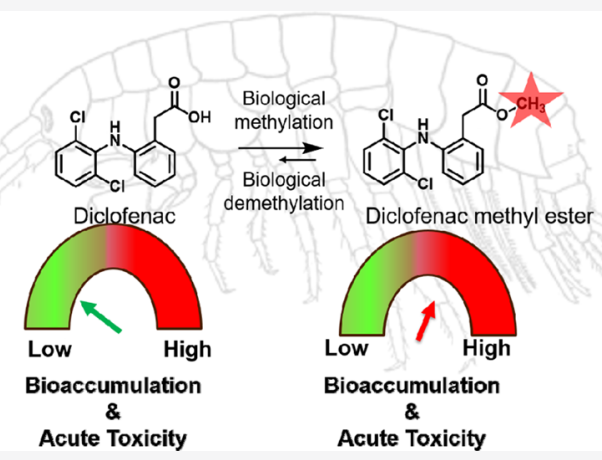
$\mathrm{kg}_{\mathrm{ww}}{ }^{-1}$ in $\mathrm{H}$. azteca and G. pulex, respectively, whereas BCFs of DCF-M310.03 was 164.5 and $104.7 \mathrm{~L} \mathrm{~kg}_{\mathrm{ww}}^{-1}$, respectively, representing a 25- to 110 -fold increase. Acute toxicity of DCF-M310.03 was also higher than the parent compound in both species, which correlated well with the increased bioconcentration potential. The $\mathrm{LC}_{50}$ of diclofenac in $H$. azteca was $216 \mathrm{mg} \mathrm{L}^{-1}$, while that of metabolite DCF-M310.03 was reduced to only $0.53 \mathrm{mg} \mathrm{L} \mathrm{L}^{-1}$, representing a 430 -fold increase in acute toxicity compared to diclofenac. DCF-M403 is less toxic than its parent compound toward $H$. azteca, which may be linked to its slightly lower hydrophobicity. Furthermore, the transformation of diclofenac to its methyl ester derivative was explored in crude invertebrate extracts spiked with an $S$-adenosylmethionine cofactor, revealing possible catalysis by an $S$-adenosylmethionine-dependent carboxylic acid methyltransferase. Methylation of diclofenac was further detected in fish hepatocytes and human urine, indicating a broader relevance. Therefore, potentially methylated metabolites of polar contaminants should be considered for a comprehensive risk assessment in the future.

\section{INTRODUCTION}

In the environment, the influence of anthropogenic activities is clearly evidenced by the pervasive occurrence of man-made chemicals as emerging contaminants, such as pharmaceuticals, which have the potential to jeopardize ecosystems and the human health. ${ }^{1-3}$ As the global population increases, economies grow as well as health care provision and insurance mechanisms expand, pharmaceutical products are being increasingly used in both human and animal applications. ${ }^{4,5}$ The ubiquitous use of pharmaceuticals in a wide range of settings has resulted in continuous emission of these compounds and their metabolites into the environment, leading to their "pseudo-persistence". ${ }^{6}$ Pharmaceuticals are designed to be biologically active, and thus, when taken up, have the potential to exert acute or chronic effects on nontarget aquatic organisms, including vertebrate and invertebrate species. For example, the pharmaceutical diclofenac is a heavily used nonsteroidal anti-inflammatory drug in both humans and livestock, with a global annual consumption of up to 1000 tons. ${ }^{7}$ Diclofenac is frequently detected in treated wastewaters, streams, rivers, lakes, and even drinking water, ${ }^{8-10}$ with the concentration in freshwater reported as high as the $\mu \mathrm{g} / \mathrm{L}$ range. ${ }^{11,12}$ Given that at $1 \mu \mathrm{g} \mathrm{L}^{-1}$ diclofenac causes cytological alterations in the liver, kidney, and gills of rainbow trout (Oncorhynchus mykiss) $)^{13}$ and, at $5 \mu \mathrm{g} \mathrm{L}^{-1}$, causes renal lesions and alterations of the gills, it is possible that environmentally determined concentrations of diclofenac may pose a risk to aquatic organisms. ${ }^{14}$ Several more studies have revealed toxic effects toward different aquatic species such as common carp (Cyprinus carpio), ${ }^{15}$ brown trout (Salmo trutta fario), ${ }^{16,17}$ rainbow trout (Oncorhynchus mykiss), ${ }^{13,14,18}$ and stickleback

Received: November 24, 2019

Revised: February 9, 2020

Accepted: February 10, 2020

Published: February 10, 2020 
(Gasterosteus aculeatus) $^{19}$ at low $\mu \mathrm{g} \mathrm{L}^{-1}$ concentrations. In a well-known incident in Pakistan and India, vulture populations were driven to near extinction after feeding on cattle carcasses containing diclofenac and its residues. ${ }^{20,21}$ As a precaution, diclofenac was added to the watch list under the European Union Water Framework Directive. ${ }^{22}$

Generally, biotransformation plays a crucial role in regulating the toxicity of chemicals. However, knowledge of relevant metabolites and their formation mechanisms is limited. ${ }^{23,24}$ Risk assessment for these bioactive pharmaceuticals typically operates under the assumption that biotransformation would result in greatly decreased toxicological risks. However, there is growing evidence indicating that metabolites of contaminants such as trenbolone, tetrabromobisphenol A, bisphenol A, and triclosan maintain the bioactive moieties, are more hydrophobic, and exhibit similar or even greater toxicity. ${ }^{25-29}$ Biotransformation via methylation could lead to more hydrophobic and thus more bioaccumulative metabolites in biological systems and has been detected in fungi, bacteria, and plants for different compounds. ${ }^{30-32}$ At present, the biotransformation and nontarget toxicity of diclofenac in aquatic organisms, especially invertebrates, is largely unexplored.

In this study, we used diclofenac as a model emerging contaminant to characterize the crucial role of biotransformation in modifying the bioaccumulation potential and toxicity of such compounds in aquatic organisms. First, we demonstrated the biotransformation patterns of diclofenac in two keystone invertebrate species of the aquatic food web: Hyalella azteca and Gammarus pulex. Second, we compared the bioaccumulation potential and acute toxicity of the parent compound, diclofenac, and its two main metabolites in these two invertebrates. Third, to determine the broader impact of biotransformation, we investigated whether methylation of diclofenac would occur in other model biological systems, such as fish hepatocytes or humans. Additionally, we screened methylation of other emerging contaminants with carboxylic and phenolic groups in the tested invertebrates.

\section{MATERIALS AND METHODS}

Chemicals, Solutions, and Test Organisms. Chemicals and solutions used in this study are provided in the Supporting Information and are listed in Tables S1 and S2. Diclofenac taurine standard was synthesized in-house based on a United States patent ${ }^{33}$ and identified by NMR spectroscopy. The synthesis protocol and the NMR data of diclofenac taurine are provided in Table S6 and Figure S1-S3. H. azteca were cultured in aerated Borgmann water (BW) in the laboratory $\left(23 \pm 2{ }^{\circ} \mathrm{C}, 16 \mathrm{~h} / 8 \mathrm{~h}\right.$ light/dark cycle), whereas G. pulex were collected from uncontaminated creeks in Switzerland (location: E 702150, N 2360850) and acclimatized for 3-5 days to the optimal culturing conditions $\left(11 \pm 2{ }^{\circ} \mathrm{C}, 12 \mathrm{~h} \mathrm{light} / 12 \mathrm{~h}\right.$ dark cycle) in an aquarium with aerated artificial pond water (APW). Details on experiments concerning $H$. azteca and $G$. pulex are provided in section SI. B. Rainbow trout hepatocytes (RT-HEPs) were prepared in-house according to a method published by Bischof et al. ${ }^{34}$

Metabolite Screening Experiments in Vivo. G. pulex (number of organisms $n=4$ per replicate, two replicates) and $H$. azteca ( $n=30$ per replicate, two replicates) were introduced into $600 \mathrm{~mL}$ glass beakers filled with $500 \mathrm{~mL}$ APW and BW, respectively. G. pulex and $H$. azteca were exposed to each chemical (i.e., diclofenac, triclosan, atorvastatin, acemetacin, naproxen, rosuvastatin) for $24 \mathrm{~h}$. An aliquot of 50 or $100 \mu \mathrm{L}$ of stock solution of each chemical in ethanol (i.e., 10.0 and $1.0 \mathrm{~g}$ $\mathrm{L}^{-1}$ ) was spiked to the media to yield an initial chemical concentration of $1 \mathrm{mg} \mathrm{L}^{-1}(\stackrel{\wedge}{=} 3.4 \mu \mathrm{M})$ and $0.2 \mathrm{mg} \mathrm{L}^{-1}\left(\hat{=}_{0} 0.68\right.$ $\mu \mathrm{M})$, respectively. The final media contained less than $0.02 \%$ organic solvent. Chestnut leaves collected in the creek (or a piece of cotton gauze $(6 \times 8 \mathrm{~cm}))$ were added into each beaker and stayed at the bottom of the beaker for G. pulex (or $H$. azteca) to perch and hide, respectively. Chestnut leaves also served as a food source for G. pulex, whereas H. azteca was fed with fish food (ground TetraMin powder). The metabolite screening was performed separately for each selected compound. Experiments were performed in a climate cabinet (Binder KB 115) maintaining the optimal conditions for $G$. pulex $\left(11 \pm 2{ }^{\circ} \mathrm{C}\right.$ and a $12 \mathrm{~h} / 12 \mathrm{~h}$ light/dark cycle $)$ and $H$. azteca $\left(23 \pm 2{ }^{\circ} \mathrm{C}\right.$ and a $16 \mathrm{~h} / 8 \mathrm{~h}$ light/dark cycle $)$. After $24 \mathrm{~h}$ exposure, animals were collected, sieved (0.6-mm sieve), quickly rinsed with ultrapure water $\left(18.2\right.$ megaohm $\left.\mathrm{cm}^{-1}\right)$, blotted dry using tissue paper, transferred into the preweighed $2 \mathrm{~mL}$ centrifuge tubes, and weighed. The exposure medium was sampled at the beginning $\left(t_{0}\right)$ and after $24 \mathrm{~h}\left(t_{24}\right)$ of the experiment. Different controls were performed in parallel, that is, chemical control (without target compounds, with organisms, leaf or cotton or fish food), organism control (without organisms, with chemical, leaf or cotton), and sorption control (only chemical in pure APW or BW medium, without organisms, leaf, or cotton) and standard control (stock solution of diclofenac in methanol, ethanol, or acetonitrile). To investigate the formation of metabolites through abiotic processes during chemical spiking or sample preparation, diclofenac in ethanol was spiked into the vials containing organisms, and then the organisms were homogenized and extracted using methanol and acetonitrile separately.

To determine the broader impact of biotransformation, we investigated the biotransformation of diclofenac in humans. Three adult healthy volunteers (two females and one male) provided their informed consent for this study. The age of volunteers was 29, 32, and 54 years old, respectively. Human urine $(\sim 10 \mathrm{~mL})$ was collected into the glass vials at $1,2,4$, and 7 or $8 \mathrm{~h}$ after oral administration of a diclofenac tablet (100 $\mathrm{mg}, 1.3$ to $2 \mathrm{mg} \mathrm{kg}^{-1}$ (bodyweight)). Urine samples were stored at $4{ }^{\circ} \mathrm{C}$ in the fridge and analyzed by using online SPE LC-HRMS/MS on the same day.

Metabolite Screening Experiments in Vitro. To elucidate the biological mechanism for methylation of diclofenac, diclofenac was spiked into the crude extract of the invertebrates and incubated for $24 \mathrm{~h}$. Briefly, G. pulex ( $n=$ $4)$ and $H$. azteca $(n=30)$ were collected in a preweighed $2 \mathrm{~mL}$ microcentrifuge tube and flash-frozen in liquid nitrogen. After addition of $1 \mathrm{~mL}$ of phosphate buffer $(0.05 \mathrm{M}, \mathrm{pH}=7.5)$, the extraction and homogenization were carried out with an ultrasonic homogenizer Labsonic M (Sartorius Stedim Biotech, Switzerland) in four cycles of $30 \mathrm{~s}$ with an amplitude of $100 \%$ and 15-30 s break in between cycles (whole process performed under ice-cooling). Afterward, the homogenates were centrifuged $\left(4^{\circ} \mathrm{C}, 10,500 \mathrm{x}\right.$, and $\left.10 \mathrm{~min}\right)$. Supernatants were collected and used as crude extracts for incubation. For in vitro incubation, $250 \mu \mathrm{L}$ of supernatant extracts was combined and mixed with $50 \mu \mathrm{L}$ of $300 \mu \mathrm{g} \mathrm{L}^{-1}(\hat{=} 1 \mu \mathrm{M})$ diclofenac in phosphate buffer and $25 \mu \mathrm{L}$ of $10 \mathrm{mM} S$-adenosylmethionine (SAM) as a co-factor in phosphate buffer and incubated for 24 $\mathrm{h}$ at $16{ }^{\circ} \mathrm{C}$ (G. pulex) and $23{ }^{\circ} \mathrm{C}$ (G. pulex and H. azteca). After 2 and $24 \mathrm{~h}, 125 \mu \mathrm{L}$ of aliquots of the incubation mixture was 
sampled and quenched by adding $175 \mu \mathrm{L}$ of acetonitrile. These samples were centrifuged $\left(4{ }^{\circ} \mathrm{C}, 10,500 \mathrm{x}, 10 \mathrm{~min}\right)$, and the supernatants were collected in $2 \mathrm{~mL}$ glass vials and kept at -80 ${ }^{\circ} \mathrm{C}$ until online SPE LC-HRMS analysis.

The rainbow trout hepatocyte experiments were performed in triplicate in accordance with the draft guidelines for hepatocyte depletion assays (OECD 319A). ${ }^{35}$ An aliquot of $5 \mu \mathrm{L}$ stock solution in ethanol was spiked into $1 \mathrm{~mL}$ of a hepatocyte suspension medium with a concentration of $2 \times$ $10^{6}$ cells $\mathrm{mL}^{-1}$ in a $7 \mathrm{~mL}$ glass vial. The concentration of diclofenac at the start of the reaction was $636 \mu \mathrm{g} \mathrm{L}^{-1}(\hat{=} 2.14$ $\mu \mathrm{M})$. After $4 \mathrm{~h}$ incubation at $13{ }^{\circ} \mathrm{C}$ under gentle shaking, the reactions were stopped by adding $4 \mathrm{~mL}$ of acetonitrile. Negative controls for abiotic reactions were run in parallel and under identical conditions using heat-inactivated hepatocytes.

Acute Toxicity of Diclofenac and Diclofenac Methyl Ester. Animals $(n=10$ per replicate, two replicates for each concentration) were separately exposed to increasing nominal concentrations of diclofenac $\left(100-500 \mathrm{mg} \mathrm{L}^{-1} \triangleq \hat{\wedge} 338-1688\right.$ $\mu \mathrm{M})$ and diclofenac methyl ester $\left(100-900 \mu \mathrm{g} \mathrm{L}^{-1} \triangleq 0.32-2.9\right.$ $\mu \mathrm{M})$. The concentrations ranges of diclofenac and diclofenac methyl ester were selected based on preliminary range-finding tests. After $24 \mathrm{~h}$ of exposure, the number of deceased animals was counted. A glass rod was used to prod immobile organisms. An organism was defined as "dead" when no movement of its appendages was observed. All living organisms were quickly rinsed with ultrapure water, dried with tissue paper, transferred into the preweighed $2 \mathrm{~mL}$ centrifuge tubes, and weighed. Media and internal concentrations of diclofenac and diclofenac methyl ester were determined using the belowdescribed online solid phase extraction (online SPE) and liquid chromatography high-resolution tandem mass spectrometry (LC-HRMS/MS) method. The medium $\mathrm{LC}_{50}$ and the internal $\mathrm{LC}_{50}$ were determined by fitting a four-parameter log-logistic model (v. 5.02, GraphPad Software Inc., U.S.A.).

Toxicity Classification. We used a quantitative structureactivity relationship (QSAR) model for baseline toxicity and classification of specific modes of action of diclofenac and its metabolites. A large compilation of QSAR studies exist for fish (embryo) and some for Daphnia magna but have not been established for G. pulex and H. azteca. Since G. pulex, H. azteca, and $D$. magna are all freshwater crustaceans, we adopted a QSAR model for D. magna ${ }^{36}$ to predict $\mathrm{LC}_{50}$ of diclofenac and its metabolite diclofenac methyl ester in G. pulex and H. azteca. The equation for $\mathrm{LC}_{50}$ (QSAR: predicted baseline toxicity) is described as follows:

$$
\log \left(\frac{1}{L_{50}}\right)=0.77 \times \log D_{\text {lipw }}(\mathrm{pH})+1.89
$$

The liposome-water partitioning coefficient $\log D_{\text {lipw }}$ of the ionic compound diclofenac was 2.6 (at $\mathrm{pH}=8$ ) calculated by Baumer et al. based on COSMOmic. ${ }^{37}$ For the neutral chemical diclofenac methyl ester, $\log D_{\text {ow }}$ (4.4) was used instead of $\log D_{\text {lipw }}(\mathrm{pH})$ (the liposome-water partitioning coefficient) in eq 1 . The toxic ratio (TR) analysis was used to classify the mode of action (MoA) (baseline toxicity or specific MoA) of diclofenac and its metabolite diclofenac methyl ester. TR was calculated based on the ratio of the $\mathrm{LC}_{50}$ predicted with the baseline toxicity QSAR and the experimental $\mathrm{LC}_{50}$ as follows (eq 2):

$$
\mathrm{TR}=\frac{\mathrm{LC}_{50}(\text { QSAR: predicted baseline toxicity })}{\mathrm{LC}_{50}(\text { experimental })}
$$

For $\mathrm{TR}<10$, a chemical is considered as a baseline toxicant; for $\mathrm{TR}>10$, a chemical is considered specifically acting or reactive. $^{38}$

Sample Preparation. In the tubes containing collected $G$. pulex and $H$. azteca, $100 \mu \mathrm{L}$ of internal standard diclofenac- $d_{4}$ $\left(100 \mu \mathrm{g} \mathrm{L}^{-1}\right), 500 \mu \mathrm{L}$ of pure methanol and $300 \mathrm{mg}$ of $1 \mathrm{~mm}$ zirconia/silica beads (BioSpec Products, Inc.) were added. A FastPrep bead beater (MP Biomedicals) was used for sample homogenization and extraction $\left(15 \mathrm{~s}\right.$ at $6 \mathrm{~m} \mathrm{~s}^{-1}$, two cycles, cooling on ice in between). The homogenate was centrifuged $\left(4{ }^{\circ} \mathrm{C}, 10,500 \mathrm{x} \mathrm{g}\right.$, and $\left.10 \mathrm{~min}\right)$ and filtered through $0.45 \mu \mathrm{m}$ regenerated cellulose filters (BGB Analytic AG). The filters were washed with $400 \mu \mathrm{L}$ methanol, and the filtrate and the wash solution were combined. The exposure media $(500 \mu \mathrm{L})$ were sampled in $2 \mathrm{~mL} \mathrm{LC}$ vials at 0 and $24 \mathrm{~h}$, spiked with 100 $\mu \mathrm{L}$ of methanol containing diclofenac- $d_{4}\left(100 \mu \mathrm{g} \mathrm{L}^{-1}\right)$ and 500 $\mu \mathrm{L}$ pure methanol, and were mixed evenly. We also examined whether the methylated metabolite of diclofenac had formed through chemical reactions in the presence of methanol during the preparation of sample extracts. In this case, the sample preparation steps for the non-exposed and exposed samples were similar to those described above but using pure acetonitrile instead of methanol.

Sample preparation of fish hepatocyte assays was conducted in a similar way to that described in the OECD TG 319A. ${ }^{35}$ Briefly, after the addition of acetonitrile solution and internal standard (10 ng of diclofenac- $\left.d_{4}\right)$, the sampled cell suspension was vortex mixed for $10 \mathrm{~min}$ at $10,500 \mathrm{x}$. Subsequently, the cellular debris was pelleted by centrifugation ( $10 \mathrm{~min}$ at 10,500 $\left.\mathrm{x} g, 4{ }^{\circ} \mathrm{C}\right)$. The supernatant sample was transferred into $4 \mathrm{~mL}$ glass vials. All samples were stored at $-20{ }^{\circ} \mathrm{C}$ until chemical analysis.

Urine samples $(2 \mathrm{~mL})$ were centrifuged $\left(4{ }^{\circ} \mathrm{C}, 10,500 \times \mathrm{g}\right.$, and $10 \mathrm{~min})$, and the supernatants were analyzed using the below-described online SPE LC-HRMS/MS method on the same day.

Chemical Analysis by LC-HRMS/MS and GC-HRMS/ MS. Details of all analytical approaches are provided in our previous study. ${ }^{39}$ Briefly, all samples were primarily cleaned up and enriched with an automated online-SPE method followed by the LC-HRMS/MS analysis using a $\mathrm{Q}$ Exactive or $\mathrm{Q}$ Exactive Plus mass spectrometer, equipped with an electrospray ionization interface (Thermo Fisher Scientific Inc.). For sample analysis, $200 \mu \mathrm{L}$ of the extract was added to $20 \mathrm{~mL}$ of headspace amber glass vials and filled up with $20 \mathrm{~mL}$ of ultrapure water to pre-enrich by online SPE. After online SPE enrichment, the chromatographic separation was achieved on an XBridge C18 column $(3.5 \mu \mathrm{m}, 2.1 \times 50 \mathrm{~mm}$, Waters $)$ at 30 ${ }^{\circ} \mathrm{C}$. The flow rate was $300 \mu \mathrm{L} \mathrm{min}{ }^{-1}$. Water with $0.1 \%$ (vol) formic acid and methanol with $0.1 \%$ (vol) formic acid were used as mobile phases $\mathrm{A}$ and $\mathrm{B}$, respectively. Full scan acquisition with a resolution of 70,000 (full width halfmaximum (FWHM) at $200 \mathrm{~m} / z$ ) was conducted in polarity switching mode followed by data-dependent MS/MS scans (five MS/MS scans in positive mode and two MS/MS scans in negative mode) with a resolution of 17,500 (FWHM at $200 \mathrm{~m} /$ $z$ ) and an isolation window of $1 \mathrm{Da}$. The detailed parameters of LC-HRMS/MS are given in Tables S3 and S4. Quantification of parent compounds and biotransformation products with the available reference standard (e.g., diclofenac methyl ester and 


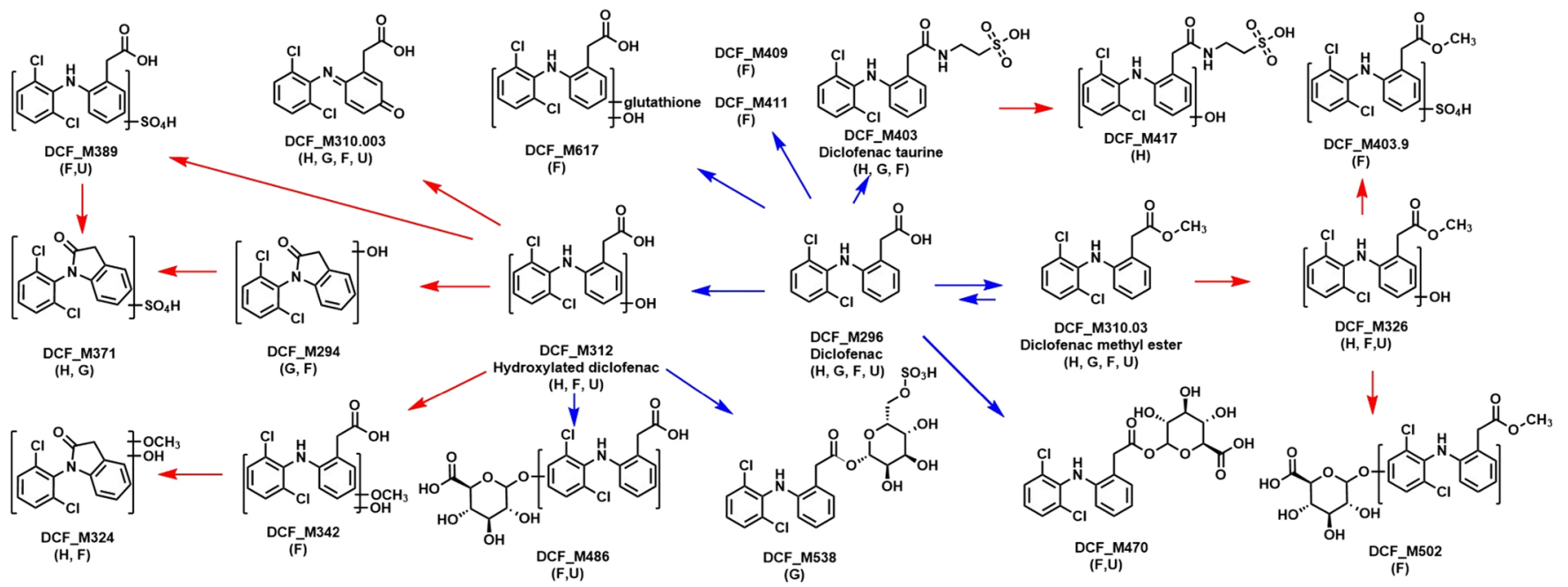

Figure 1. Proposed biotransformation pathways of diclofenac based on the organism-specific detection in H. azteca (H), G. pulex (G), and rainbow trout (Oncorhynchus mykiss) hepatocytes (F) and humans (U). More detailed information on the individual metabolites can be found in section SI. $\mathrm{J}$. and Table S8. Red arrows indicate phase I reactions, and blue arrows indicate phase II reactions. Please note that all the metabolites are displayed in the neutral form. The number in the abbreviation of metabolites' name stands for the molecular mass of the detected ion. Please note that identification confidence levels according to Schymanski et al. ${ }^{40}$ are shown in Table S8.

diclofenac taurine) was performed with the respective standard calibration method using the software TraceFinder v4.1 (Thermo Scientific). To test if diclofenac methyl ester could be formed during chemical analysis, diclofenac stock solutions were prepared in methanol, ethanol, or acetonitrile and then analyzed by LC-HRMS/MS. Additionally, acetonitrile with $0.1 \%$ (vol) formic acid was used instead of methanol with $0.1 \%$ (vol) formic acid as mobile phase B together with mobile phase A (water with $0.1 \%$ (vol) formic acid) to verify whether methylation of diclofenac would occur under LC-MS/MS conditions.

Triclosan methyl ether was analyzed by gas chromatography high-resolution tandem mass spectrometry (GC-HRMS/MS) with positive mode electron ionization ( $Q$ Exactive, Thermo Fisher Scientific Inc.). For separation, we used an RTX-5MS column $(15 \mathrm{~m} \times 0.25 \mathrm{~mm}, 0.25 \mu \mathrm{m}$ film thickness $)$ equipped with a guard column $(5 \mathrm{~m} \times 0.25 \mathrm{~mm})$. The column oven program started at $60{ }^{\circ} \mathrm{C}$ was held for $1 \mathrm{~min}$, increased at 10 ${ }^{\circ} \mathrm{C} / \mathrm{min}$ to $300{ }^{\circ} \mathrm{C}$, and was then held for $3 \mathrm{~min}$. The transfer line temperature was $280{ }^{\circ} \mathrm{C}$. Splitless injection of $1 \mu \mathrm{L}$ was used at an injector temperature of $260{ }^{\circ} \mathrm{C}$. Data analysis of triclosan methyl ether was performed by external standard calibration using the software Xcalibur Quan Browser (Thermo Scientific).

Identification of Metabolites and Structure Elucidation. The acquired HRMS/MS raw data were analyzed by Compound Discoverer software 2.1 (CD2.1) (Thermo Scientific; for criteria and parameter settings, see Table S5) with a suspect and non-target screening approach. Treatment and different control groups (i.e., chemical control, organism control, and sorption control) were compared by CD2.1 to generate the potential candidate list. The candidates were identified based on their unique presence in the treatment and/or at least 5-fold increase in the treatment compared to the control, peak intensity $>10^{5}$, and $\geq 3$ scans in the extracted ion chromatograms. For the screening of possible metabolites, the generated candidate list was compared to the mass list of predicted metabolites, which was based on (i) in silico manual prediction of metabolites considering the most common enzymatic biotransformation reactions and (ii) already identified metabolites reported in any organism in the scientific literature. For non-target screening, the generated candidate list from CD2.1 was filtered with (i) a peak area threshold of $0.1 \%$ of the parent compound and (ii) an integrated intensity ratio between treatment and control samples of at least 5 .

Structure elucidation was based on the exact mass, isotopic pattern ( $\mathrm{Cl}$ pattern), MS/MS spectral information, MS/MS information from the available literature, in silico fragmentation tool (Mass Frontier v 7.0, HighChem), and reference standards. Finally, confidence levels of the metabolite identification were proposed according to Schymanski et al. ${ }^{40}$

\section{RESULTS AND DISCUSSION}

Biotransformation of Diclofenac Leads to Various Metabolites in Different Species. Metabolite screening experiments in the presence of $H$. azteca and G. pulex were carried out with exposure to diclofenac for $24 \mathrm{~h}$. Suspect and non-target screening strategies were applied to comprehensively identify metabolites in the test species using the data acquired with LC-HRMS/MS. The isotopic pattern of chlorine (Cl) was used to support the identification of $\mathrm{Cl}$-containing diclofenac metabolites. To determine the broader impact of diclofenac biotransformation, we investigated the biotransformation of diclofenac in other biological systems, including fish hepatocytes and humans. In all tested species, the transformation of diclofenac was detected (Figure 1). In total, 17 diclofenac metabolites were detected across the tested biological systems, with nine detected in $H$. azteca and $G$. pulex and eight in fish hepatocytes and human urine (Figure 1 and Figure S4). The postulated biotransformation reactions included methylation, hydroxylation, dehydration, and conjugation with taurine, glutathione, glucose-sulfate, and glucuronic acid (Figure 1 and Table S8). A biotransformation pathway based on the tentative chemical structures and biological reaction rationale is shown in Figure 1. Among these metabolites, we unambiguously confirmed the structures of diclofenac methyl ester (DCF-M310.03) and diclofenac taurine (DCF-M403) using authentic reference standards (for 
details of the synthesis and NMR-based identification of diclofenac taurine; see section SI. E and Figure S1-S3). After $24 \mathrm{~h}$ exposure at media concentration of $0.2 \mathrm{mg} \mathrm{L}^{-1}$ diclofenac, the internal concentrations of diclofenac and biotransformed products DCF-M403 and DCF-M310.03 in exposed H. azteca were 120-158 $\mathrm{ng} \mathrm{g}_{\mathrm{ww}}{ }^{-1}$ (wet weight), 1761-1996 $\mathrm{ng} \mathrm{g}_{\mathrm{ww}}{ }^{-1}$, and 0.7-116.5 $\mathrm{ng} \mathrm{g}_{\mathrm{ww}}{ }^{-1}$, respectively, using different extraction solvents (i.e., acetonitrile, ethanol, methanol, acetone, ethyl acetate). These results suggest that the ratios of biotransformation products to parent compound were 12-17 for DCFM403 and 0.01-0.7 for DCF-M310.03. A subsequent extraction with acetonitrile followed by methanol indicates that the extraction efficiency of DCF-M10.03 inside of $H$. azteca is increased with methanol. Detailed quantification and discussions are given in section SI. F, Figure S4, and Table S7.

Taurine conjugation of diclofenac (Figure 1, entries DCFM403) has previously been proposed as a minor reaction pathway in both mice ${ }^{41}$ and dogs. ${ }^{42}$ Here, for the first time, we have shown this to be a major pathway in the transformation of diclofenac in small aquatic invertebrates (Figure 1 and Figure S4). Similarly, taurine conjugation of azoxystrobin was identified for $H$. azteca in our previous study. ${ }^{39}$ In general, taurine conjugates of any compound are formed from compounds carrying a carboxylic acid group and have been identified in crustacean, ${ }^{43,44}$ fish, ${ }^{45,46}$ and humans. ${ }^{47,48}$ Hydroxylation and conjugation of diclofenac with glutathione, glucuronic acid, and sulfate (Figure 1, entries DCF-M312, DCF-M371, DCF-M470, and DCF-M486) have been also reported in other species, such as Mediterranean mussels ( Mytilus galloprovincialis) and the rainbow trout (Oncorhynchus mykiss). ${ }^{18,49-52}$ Species specificity for the metabolic reactions was observed, for example, glucuronic acid conjugation (Figure 1, entries DCF-M470 and M486) was the major transformation product of diclofenac detected in humans $^{53}$ and fish hepatocytes but was not observed in the tested invertebrates (Figure 1, entries DCF-M470 and M486) nor has it previously been detected in plants. ${ }^{54}$ Instead, glucose or amino acid (e.g., glutathione or glutamic acid) conjugations of diclofenac were predominant reactions in invertebrates (Figure 1, entries DCF-M538), mussels, ${ }^{52}$ or plants. ${ }^{54}$

Among all metabolites, DCF-M310.03 via methylation of diclofenac emerged as an unexpected metabolite. Therefore, we have tried to rule out the possibility that DCF-M310.03 had formed as an artifact of our sample preparation or analysis procedures. To do so, several control samples were prepared to assess the formation of DCF-M310.03 through unexpected chemical reactions or as procedural artifacts (i.e., a falsepositive result). In the absence of diclofenac (chemical control), neither diclofenac nor any of its metabolites were detected, suggesting that there was no background contamination. When applying diclofenac without organisms or in pure media, no obvious degradation of diclofenac or formation of its metabolites was observed after $24 \mathrm{~h}$, suggesting that there was no detectable abiotic transformation of diclofenac in the test system. We also examined whether DCF-M310.03 might have formed by chemical reactions in the presence of methanol during the preparation of stock solutions, sample extraction, or LC separations. The results showed that no detectable amount of DCF-M310.03 was formed during sample extraction or in LC mobile phase containing methanol and $0.1 \%$ formic acid or acetonitrile and $0.1 \%$ formic acid, suggesting that methylation did not occur during sample preparation and LC-MS instrumental analysis. No DCF-M310.03 was detected in the ethanol stock solution of diclofenac sodium salt or in the methanol stock solution of diclofenac sodium salt. Only minor amounts of DCF-M310.03 ( $<0.17 \%$ with respect to diclofenac) were detected in the methanol stock solution of the free acid of diclofenac, formed either by methylation in the stock solution or more probably already present as an impurity in the diclofenac free acid standard. In this study, we used diclofenac sodium salt for preparing the diclofenac stock solution. In conclusion, methylation due to the use of methanol as a solvent was negligible under the current experimental conditions.

Methylation of diclofenac, which had been tentatively proposed for rainbow trout (Oncorhynchus mykiss), ${ }^{18}$ has been unambiguously identified and quantified for the first time in the current study in the metabolic pathway of the selected invertebrates. It is worth noting that methylation of diclofenac emerged as an unexpected biotransformation pathway in $G$. pulex, $H$. azteca, fish hepatocytes, and human urine. DCFM310.03 was detected in fish hepatocytes after $4 \mathrm{~h}$ exposure and in human urine after oral administration of diclofenac (1$8 \mathrm{~h}$, formation kinetics shown in Figure S5). In other studies, methylated metabolites have been previously identified in microorganisms such as methylation of tetrabromobisphenol A $(\mathrm{TBBPA})^{28}$ and bisphenol A (BPA) in bacteria ${ }^{29}$ as well as bezafibrate in algae. ${ }^{55}$ To determine the environmental relevance, we performed a retrospective analysis of digitally stored HRMS data to investigate DCF-M310.03 in muscle samples of 10 fish and 14 gammarid samples (diclofenac concentration: $1-5 \mathrm{ng} \mathrm{g}_{\mathrm{ww}}{ }^{-1}$ ) collected in wastewater-impacted streams. ${ }^{3}$ The retrospective analysis revealed that DCFM310.03 was not present in the collection of field samples of fish and gammarids. However, based on the ratio of DCF and DCF-M310.03 in our laboratory experiments and the limit of quantitation (LOQ) of DCF-M310.03 (low $\mathrm{ng} \mathrm{g}^{-1}$ ), we estimated the concentrations of DCF-M310.03 in field samples to have been below the LOQ.

We further screened five more widely used pharmaceuticals and pesticides with hydroxyl or carboxyl group (triclosan, atorvastatin, acemetacin, naproxen, and rosuvastatin) to test whether a methylation reaction was detectable for these compounds in invertebrates. We found that the methylation of triclosan occurred in G. pulex and $H$. azteca but was not observed for atorvastatin, acemetacin, naproxen, or rosuvastatin. The structural differences may contribute to the different methylation among these chemicals. The formation of triclosan methyl ether was confirmed using an authentic reference standard (see section SI. J). The methylation takes place at the hydroxyl group of triclosan leading to the methyl ether.

Methylated products may also undergo enzyme-catalyzed demethylation, which was confirmed by exposing $H$. azteca and G. pulex to only DCF-M310.03 for $24 \mathrm{~h}$, as diclofenac was detected in both species. Demethylation was also observed for triclosan methyl ether in both invertebrates (see section SI. J). Demethylation of DCF-M310.03 is most probably catalyzed by ester hydrolases, while demethylation of triclosan methyl ether is catalyzed by cytochrome P450. ${ }^{56}$ Our observation is in line with previous studies describing the conversion of pollutant conjugates into their parental form (e.g., sulfamethoxazole, estrogens, trenbolone, triclosan, and carbamazepine) in the environment. ${ }^{25,26,57-59}$

Formation of Diclofenac Methyl Ester by Enzymes in the Crude Extract. We hypothesized that the DCF-M310.03 was formed from enzymatic reactions via methyltransferases in 
the biological systems. Two $S$-adenosylmethionine-dependent $O$-methyltransferases are known, namely, the caffeoyl-CoA $O$ methyltransferases, which catalyze phenolic groups, and the carboxylic acid $O$-methyltransferases, which catalyze carboxyl groups. $^{60,61}$ Therefore, in vitro crude extracts from G. pulex and $H$. azteca were incubated with the co-factor $S$ adenosylmethionine and diclofenac for up to $24 \mathrm{~h}$. In the control groups of the in vitro incubation experiment, no DCFM310.03 was found. Methylation of diclofenac was detected in the in vitro experiments of enzymes extracted from adult $H$. azteca. This was not the case for either juvenile $H$. azteca or adult G. pulex in vitro. A possible explanation for this may be that the activity of the responsible enzymes might be lost or inhibited in the crude extract. It might also be that the activity of the responsible enzyme(s) varies depending on the species and age. Our results from the in vitro enzymatic reactions indicate that methylation of diclofenac probably is catalyzed by the carboxylic acid $O$-methyltransferases in the tested biological systems. However, transformation by other unknown enzymes or bacteria in the crude extract cannot be fully excluded. Similarly, $O$-methyltransferases have been identified in plants, ${ }^{60}$ bacteria, ${ }^{61,62}$ yeast, ${ }^{63}$ and humans, ${ }^{64}$ making this conclusion plausible.

Significantly Higher Bioconcentration of the Metabolite Diclofenac Methyl Ester versus Diclofenac. The formation of diclofenac methyl ester (DCF-M310.03) leads to significantly altered physicochemical properties. A physicochemical property that is of importance to toxicity and bioaccumulation is changed by the methylation of the carboxylic group. The partitioning coefficient of diclofenac between octanol and water $\left(\log D_{\text {ow }}\right.$ ) is 0.9 (anionic at medium $\mathrm{pH} 7.9$ ), while $\log D_{\text {ow }}$ increases to 4.4 for DCFM310.03 (neutral compound). Accordingly, bioconcentration potential and biological activity of DCF-M310.03 could be elevated compared to diclofenac and other known metabolites. Bioconcentration factors (BCFs) were calculated based on (i) in silico simulations using EPI 3.0 and (ii) the ratio of the internal concentration of the chemical in the organisms to the concentration of the chemical in the exposure medium at a steady state. The predicted BCFs of diclofenac and DCFM310.03 (EPI 3.0 simulation) were 1.3 and $351 \mathrm{~L} \mathrm{~kg}^{-1}$, respectively, for lower trophic level fish (Figure 2A), indicating a higher bioconcentration potential of DCF-M310.03 than
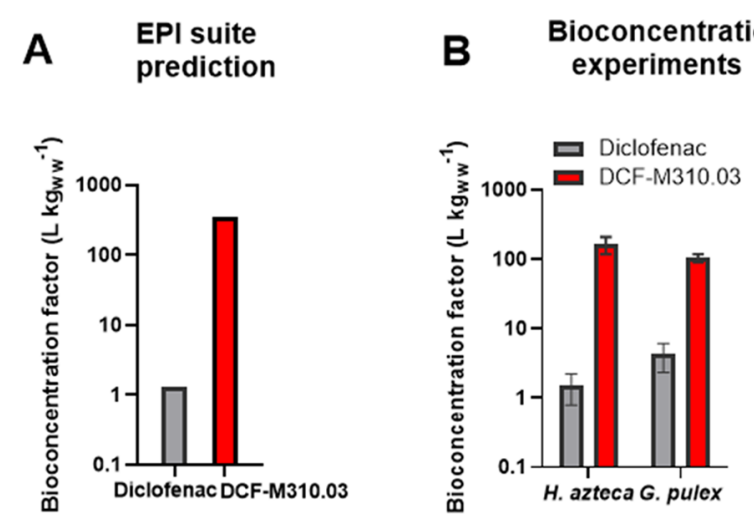

Figure 2. Comparison of the bioconcentration potential of diclofenac and diclofenac methyl ester (DCF-M310.03). Bioconcentration factor of diclofenac and DCF-M310.03 determined by (A) in silico prediction using EPI suite ${ }^{65}$ and (B) experimentally in $H$. azteca and G. pulex under static conditions after $24 \mathrm{~h}$. diclofenac. The predicted BCFs of diclofenac and DCFM310.03 were similar to the BCFs found in the experiment. The experimentally determined BCFs of diclofenac were 0.5 and $3.2 \mathrm{~L} \mathrm{~kg} \mathrm{ww}^{-1}$ in $H$. azteca and G. pulex, respectively, whereas BCFs of DCF-M310.03 was 164.5 and $104.7 \mathrm{~L} \mathrm{~kg}_{\text {ww }}{ }^{-1}$ (Figure 2B), respectively, which corresponds to a 25- to 110 fold increase. Thus, the higher BCFs of DCF-M310.03 compared to those of diclofenac in both organisms can actually be explained by the higher hydrophobicity of DCFM310.03.

Comparison of the Toxicity between Diclofenac and Its Major Metabolites. The toxicity of two major metabolites (i.e., DCF-M310.03 and DCF-M403) was compared to the parent compound in two invertebrate species. The acute toxicity of diclofenac and DCF-M310.03 was assessed by deriving the $24 \mathrm{~h}$ media $\mathrm{LC}_{50}$ values for $H$. azteca and G. pulex based on mortality. The $\mathrm{LC}_{50}$ of diclofenac in media was 216 and $175 \mathrm{mg} \mathrm{L}^{-1}$ for $H$. azteca and G. pulex, respectively, indicating relatively low acute compared to environmental concentrations (Figure 3A). However, the strongly reduced
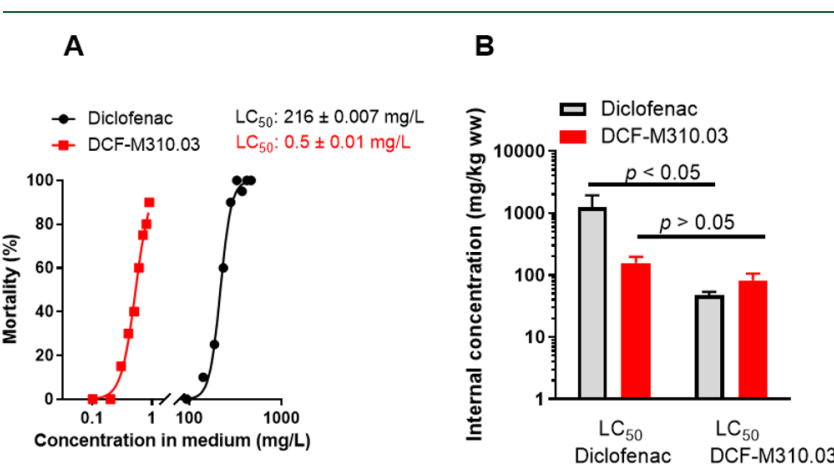

Figure 3. Lethal toxicity of diclofenac and DCF-M310.03 toward $H$. azteca. (A) Medium concentration-response (mortality) curves of lethal toxicity of diclofenac and DCF-M310.03. (B) Internal concentrations of diclofenac and DCF-M310.03 in H. azteca at the corresponding media $\mathrm{LC}_{50}$ 's. Student's $t$-test, unpaired.

media $\mathrm{LC}_{50}$ of $0.53 \mathrm{mg} \mathrm{L}^{-1}$ obtained for DCF-M310.03 with $H$. azteca represents a 430-fold increase in acute toxicity compared to diclofenac (Figure 3A). The $\mathrm{LC}_{50}$ of DCFM310.03 (>1 $\mathrm{mg} \mathrm{L}^{-1}$ ) in media was obtained for G. pulex but could not be exactly determined due to the limited water solubility of DCF-M310.03 $\left(<1 \mathrm{mg} \mathrm{L}^{-1}\right)$. Our results are consistent with previous observations that the methylated metabolites of BPA are more toxic than the parent compound, leading to increased toxicity to the developing zebrafish (Danio rerio) embryo. ${ }^{29}$

Internal concentrations of the chemicals reflect the organism's actual exposure that links to the observed toxicological effects. We therefore determined the internal concentrations (body residue) of diclofenac and DCFM310.03 in H. azteca using LC-HRMS/MS (Figure S6). For $H$. azteca at media $\mathrm{LC}_{50}$ concentrations of diclofenac $(216$ $\left.\mathrm{mg} \mathrm{L}^{-1}\right)$ or DCF-M310.03 $\left(0.5 \mathrm{mg} \mathrm{L}^{-1}\right)$ as shown in Figure $3 \mathrm{~A}$, very similar internal concentrations of DCF-M310.03 of $157 \pm 43$ and $83 \pm 23 \mathrm{mg} \mathrm{kg}^{-1}$ ww were determined, respectively. In contrast, the internal levels of diclofenac significantly differed $(p<0.05)$ by one order of magnitude (Figure 3B). This observation indicates that DCF-M310.03 likely contributes more to the observed toxicity, while both 
diclofenac and DCF-M310.03, as a mixture, might be of relevance.

The acute toxicity of another major metabolite diclofenac taurine DCF-M403 was also compared to the data of the parent compound diclofenac. Due to the limited availability of synthesized DCF-M403 (section SI. E and Figure S1-S3), we were only able to determine the toxicity difference at a concentration of $220 \mathrm{mg} \mathrm{L}^{-1}$ (similar to media $\mathrm{LC}_{50}$ of diclofenac). In two separate batches, $H$. azteca was exposed to $220 \mathrm{mg} \mathrm{L}^{-1}$ diclofenac or DCF-M403 for $24 \mathrm{~h}$ each. About $50 \%$ of the organisms died at $220 \mathrm{mg} \mathrm{L}^{-1}$ diclofenac after $24 \mathrm{~h}$, while no death was observed at $220 \mathrm{mg} \mathrm{L}^{-1}$ DCF-M403. These results suggest that DCF-M403 is less toxic than its parent compound diclofenac toward $H$. azteca, which may be linked to the slightly lower hydrophobicity of DCF-M403 $\left(\log D_{\text {ow }}\right.$ $(\mathrm{pH} 7.9), 0.3)$ as compared to diclofenac $\left(\log D_{\text {ow }}(\mathrm{pH} 7.9)\right.$, $0.9)$.

Mode of Action of Diclofenac and Its Metabolite Diclofenac Methyl Ester. The mode of action (MoA) for acute toxicity of diclofenac and DCF-M310.03 toward $H$. azteca at environmentally relevant $\mathrm{pH} 7.9$ was evaluated. Toxic ratios (TR) of 3.3 and 0.2 were determined for diclofenac and DCF-M310.03, respectively, which were within the baseline toxicity range $(0.1<\mathrm{TR}<10)$, meaning that both compounds are classifiable as baseline toxicants toward $H$. azteca. In contrast, diclofenac was recently classified as a specific toxic chemical with a high $\mathrm{TR}(\mathrm{TR}=35)$ toward zebrafish, explained with the specific cyclooxygenase inhibition (COX) assay. ${ }^{38}$ This discrepancy may be attributed to differences in the diclofenac-COX interactions between invertebrates and vertebrates.

Environmental Implications. We have shown that diclofenac unexpectedly produces a more bioaccumulative and toxic metabolite in invertebrates, fish, and humans that could contribute to enhanced toxicity not previously reported. In addition to diclofenac, we also observed that the methylation of triclosan occurred in two keystone invertebrates, while methylation was not observed for atorvastatin, acemetacin, naproxen, and rosuvastatin in the same species. These findings indicate that methylation is relevant only for certain compounds. Methylation leads to more hydrophobic metabolites for some polar emerging contaminants, which in turn leads to enhanced bioaccumulation and associated toxicity across different nontarget species. Accordingly, potentially methylated metabolites should be screened to allow for better risk assessment of polar contaminants in the future. A full consideration of both methylation and demethylation conversion is needed to better understand the dynamics of the methylated products and their precursors in aquatic organisms.

Environmental concentrations of most contaminants are much lower than the concentrations used in this study, which were necessary to identify the metabolites. In future studies, methylated metabolites should be screened in field samples; however, extremely sensitive analytical methods are necessarily required.

\section{ASSOCIATED CONTENT}

\section{SI Supporting Information}

The Supporting Information is available free of charge at https://pubs.acs.org/doi/10.1021/acs.est.9b07127.

Supplementary texts; tables containing the list of substances, other chemicals and solvents, time schedules of online SPE and liquid chromatography (LC) gradient used for reversed-phase LC, settings used for the suspect and nontarget screening of metabolites with Compound Discoverer v2.1, ${ }^{1} \mathrm{H}$ and ${ }^{13} \mathrm{C}$ NMR data of diclofenac taurine conjugate, internal concentrations of diclofenac and its two major metabolites in $H$. azteca, overview of MS parameters and MS data collected for diclofenac and its metabolites formed in the aquatic invertebrates $H$. azteca and G. pulex as well as in fish hepatocytes and humans, extraction efficiency of different organic solvents for diclofenac and its two major metabolites in H. azteca; and figures containing chemical structure of diclofenac taurine conjugate with an indication of positions used for NMR resonance assignments, various NMR spectra of diclofenac taurine conjugate, heat map of response intensities of diclofenac metabolites in different biological systems, formation kinetics of diclofenac and diclofenac methyl ester in human urine, internal concentration-response curves of lethal toxicity (internal LC50) of diclofenac and diclofenac methyl ester in H. azteca, and LC-HRMS/MS and GC-HRMS/ MS spectra of metabolites (PDF)

\section{AUTHOR INFORMATION}

\section{Corresponding Authors}

Qiuguo Fu - Eawag, Swiss Federal Institute of Aquatic Science and Technology, 8600 Dübendorf, Switzerland; 10 orcid.org/ 0000-0002-4227-5948; Email: qiuguo.fu@eawag.ch

Juliane Hollender - Eawag, Swiss Federal Institute of Aquatic Science and Technology, 8600 Dübendorf, Switzerland; Institute of Biogeochemistry and Pollutant Dynamics, ETH Zürich, 8092 Zürich, Switzerland; 이이.org/0000-0002-4660-274X; Phone: +41 58765 5493; Email: juliane.hollender@ eawag.ch; Fax: +41 587655893

\section{Authors}

Davide Fedrizzi - Eawag, Swiss Federal Institute of Aquatic Science and Technology, 8600 Dübendorf, Switzerland

Verena Kosfeld - Fraunhofer Institute for Molecular Biology and Applied Ecology IME, 57392 Schmallenberg, Germany; Institute for Environmental Research (Biology V), 52074 Aachen, Germany

Christian Schlechtriem - Fraunhofer Institute for Molecular Biology and Applied Ecology IME, 57392 Schmallenberg, Germany; Institute for Environmental Research (Biology V), 52074 Aachen, Germany

Vera Ganz - Eawag, Swiss Federal Institute of Aquatic Science and Technology, 8600 Dübendorf, Switzerland; Institute of Biogeochemistry and Pollutant Dynamics, ETH Zürich, 8092 Zürich, Switzerland

Samuel Derrer - Eawag, Swiss Federal Institute of Aquatic Science and Technology, 8600 Dübendorf, Switzerland

Daniel Rentsch - EMPA, Swiss Federal Laboratories for Materials Science and Technology, 8600 Dübendorf, Switzerland

Complete contact information is available at: https://pubs.acs.org/10.1021/acs.est.9b07127

\section{Notes}

The authors declare no competing financial interest. 


\section{ACKNOWLEDGMENTS}

This research was financially supported by the Swiss National Science Foundation (grant number 205320165935) and the European Chemical Industry Council's Long-Range Research Initiative program (Cefic-LRi) (ECO 40 project). The NMR hardware was partially granted by the Swiss National Science Foundation (SNSF, grant no. 206021_150638/1). We thank Martin Jones, Andrea Rösch(all Eawag), and Marion Junghans (Ecotox Centre) for helpful discussion and proofreading of the manuscript. Furthermore, we appreciate Markus Zennegg (Empa) and Jakov Bolotin (Eawag) for support with the GC-HRMS/MS analysis as well as Marco Fleischmann and Cornel Niederhauser for assistance with the DCF-M403 standard synthesis. We thank volunteers for their participation in the trial and Michael Patrick (Eawag) for help in the sample preparation. We also thank ChemAxon (Budapest, Hungary) for an academic license of Marvin/Calculator Plugins. Last but not least, we thank the four anonymous reviewers for taking their time to carefully review our manuscript and provide valuable comments that contributed to the improvement of this manuscript.

\section{REFERENCES}

(1) Schwarzenbach, R. P.; Escher, B. I.; Fenner, K.; Hofstetter, T. B.; Johnson, C. A.; Von Gunten, U.; Wehrli, B. The challenge of micropollutants in aquatic systems. Science 2006, 313, 1072-1077.

(2) Fent, K.; Weston, A. A.; Caminada, D. Ecotoxicology of human pharmaceuticals. Aquat. Toxicol. 2006, 76, 122-159.

(3) Munz, N. A.; Fu, Q.; Stamm, C.; Hollender, J. Internal Concentrations in Gammarids Reveal Increased Risk of Organic Micropollutants in Wastewater-Impacted Streams. Environ. Sci. Technol. 2018, 52, 10347-10358.

(4) Klein, E. Y.; Van Boeckel, T. P.; Martinez, E. M.; Pant, S.; Gandra, S.; Levin, S. A.; Goossens, H.; Laxminarayan, R. Global increase and geographic convergence in antibiotic consumption between 2000 and 2015. Proc. Natl. Acad. Sci. U. S. A. 2018, No. E3463.

(5) Kantor, E. D.; Rehm, C. D.; Haas, J. S.; Chan, A. T.; Giovannucci, E. L. Trends in prescription drug use among adults in the United States from 1999-2012. JAMA 2015, 1818.

(6) Depledge, M. Reduce drug waste in the environment. Nature 2011, 478, 36 .

(7) Zhang, Y.; Geißen, S. U.; Gal, C. Carbamazepine and diclofenac: removal in wastewater treatment plants and occurrence in water bodies. Chemosphere 2008, 73, 1151-1161.

(8) Reemtsma, T.; Weiss, S.; Mueller, J.; Petrovic, M.; González, S.; Barcelo, D.; Ventura, F.; Knepper, T. P. Polar pollutants entry into the water cycle by municipal wastewater: A European perspective. Environ. Sci. Technol. 2006, 40, 5451-5458.

(9) Jelic, A.; Gros, M.; Ginebreda, A.; Cespedes-Sánchez, R.; Ventura, F.; Petrovic, M.; Barcelo, D. Occurrence, partition and removal of pharmaceuticals in sewage water and sludge during wastewater treatment. Water Res. 2011, 45, 1165-1176.

(10) Morasch, B.; Bonvin, F.; Reiser, H.; Grandjean, D.; De Alencastro, L. F.; Perazzolo, C.; Cheèvre, N.; Kohn, T. Occurrence and fate of micropollutants in the Vidy Bay of Lake Geneva, Switzerland. Part II: Micropollutant removal between wastewater and raw drinking water. Environ. Toxicol. Chem. 2010, 29, 1658-1668.

(11) Ort, C.; Hollender, J.; Schaerer, M.; Siegrist, H. Model-based evaluation of reduction strategies for micropollutants from wastewater treatment plants in complex river networks. Environ. Sci. Technol. 2009, 43, 3214-3220.

(12) Malaj, E.; von der Ohe, P. C.; Grote, M.; Kühne, R.; Mondy, C. P.; Usseglio-Polatera, P.; Brack, W.; Schäfer, R. B. Organic chemicals jeopardize the health of freshwater ecosystems on the continental scale. Proc. Natl. Acad. Sci. 2014, 111, 9549-9554.
(13) Triebskorn, R.; Casper, H.; Heyd, A.; Eikemper, R.; Köhler, H.R.; Schwaiger, J. Toxic effects of the non-steroidal anti-inflammatory drug diclofenac. Aquat. Toxicol. 2004, 68, 151-166.

(14) Schwaiger, J.; Ferling, H.; Mallow, U.; Wintermayr, H.; Negele, R. D. Toxic effects of the non-steroidal anti-inflammatory drug diclofenac. Part I: Histopathological alterations and bioaccumulation in rainbow trout. Aquat. Toxicol. 2004, 68, 141-150.

(15) Islas-Flores, H.; Gómez-Oliván, L. M.; Galar-Martínez, M.; Colín-Cruz, A.; Neri-Cruz, N.; García-Medina, S. Diclofenac-induced oxidative stress in brain, liver, gill and blood of common carp (Cyprinus carpio). Ecotoxicol. Environ. Saf. 2013, 92, 32-38.

(16) Schwarz, S.; Schmieg, H.; Scheurer, M.; Köhler, H. R.; Triebskorn, R. Impact of the NSAID diclofenac on survival, development, behaviour and health of embryonic and juvenile stages of brown trout, Salmo trutta f. fario. Sci. Total Environ 2017, 607-608, $1026-1036$.

(17) Hoeger, B.; Köllner, B.; Dietrich, D. R.; Hitzfeld, B. Waterborne diclofenac affects kidney and gill integrity and selected immune parameters in brown trout (Salmo trutta f. fario). Aquat. Toxicol. 2005, 75, 53-64.

(18) Mehinto, A. C.; Hill, E. M.; Tyler, C. R. Uptake and Biological Effects of Environmentally Relevant Concentrations of the Nonsteroidal Anti-inflammatory Pharmaceutical Diclofenac in Rainbow Trout (Oncorhynchus mykiss). Environ. Sci. Technol. 2010, 44, $2176-$ 2182.

(19) Näslund, J.; Fick, J.; Asker, N.; Ekman, E.; Larsson, D. G. J.; Norrgren, L. Diclofenac affects kidney histology in the three-spined stickleback ( Gasterosteus aculeatus ) at low $\mu \mathrm{g} / \mathrm{L}$ concentrations. Aquat. Toxicol. 2017, 189, 87-96.

(20) Prakash, V.; Pain, D. J.; Cunningham, A. A.; Donald, P. F.; Prakash, N.; Verma, A.; Gargi, R.; Sivakumar, S.; Rahmani, A. R. Catastrophic collapse of indian white-backed Gyps bengalensis and long-billed Gyps indicus vulture populations. Biol. Conserv. 2003, 109, 381-390.

(21) Oaks, J. L.; Gilbert, M.; Virani, M. Z.; Watson, R. T.; Meteyer, C. U.; Rideout, B. A.; Shivaprasad, H. L.; Ahmed, S.; Chaudhry, M. J. I.; Arshad, M.; Mahmood, S.; Ali, A.; Khan, A. A. Diclofenac residues as the cause of vulture population decline in Pakistan. Nature 2004, 427, 630-633.

(22) Union, E. Commission Implementing Regulation (EU) 2015/495 of 20 March 2015 establishing a watch list of substances for Union-wide monitoring in the field of water policy pursuant to Directive 2008/105/ EC of the European Parliament and of the Council; International Motor Vehicle Inspection Committee, 2015; Vol. L78/40.

(23) Brausch, J. M.; Connors, K. A.; Brooks, B. W.; Rand, G. M. Human pharmaceuticals in the aquatic environment: a review of recent toxicological studies and considerations for toxicity testing. In Reviews of Environmental Contamination and Toxicology Volume 218; Springer: 2012; pp 1-99.

(24) Naidoo, V.; Swan, G. E. Diclofenac toxicity in Gyps vulture is associated with decreased uric acid excretion and not renal portal vasoconstriction. Comp. Biochem. Physiol. - C Toxicol. Pharmacol. 2009, 149, 269-274.

(25) Qu, S.; Kolodziej, E. P.; Long, S. A.; Gloer, J. B.; Patterson, E. V.; Baltrusaitis, J.; Jones, G. D.; Benchetler, P. V.; Cole, E. A.; Kimbrough, K. C.; Tarnoff, M. D.; Cwiertny, D. M. Product-to-Parent Reversion of Trenbolone: Unrecognized Risks for Endocrine Disruption. Science 2013, 342, 347-351.

(26) Fu, Q.; Liao, C.; Du, X.; Schlenk, D.; Gan, J. Back Conversion from Product to Parent: Methyl Triclosan to Triclosan in Plants. Environ. Sci. Technol. Lett. 2018, 5, 181-185.

(27) Ashrap, P.; Zheng, G.; Wan, Y.; Li, T.; Hu, W.; Li, W.; Zhang, H.; Zhang, Z.; Hu, J. Discovery of a widespread metabolic pathway within and among phenolic xenobiotics. Proc. Natl. Acad. Sci. U. S. A. 2017, 114, 6062-6067.

(28) George, K. W.; Häggblom, M. M. Microbial O-methylation of the flame retardant tetrabromobisphenol-A. Environ. Sci. Technol. 2008, 42, 5555-5561. 
(29) McCormick, J. M.; Es, T. V.; Cooper, K. R.; White, L. A.; Häggblom, M. M. Microbially mediated O-methylation of bisphenol a results in metabolites with increased toxicity to the developing Zebrafish (Danio rerio) embryo. Environ. Sci. Technol. 2011, 45, 6567-6574.

(30) Kim, Y. H.; Moody, J. D.; Freeman, J. P.; Brezna, B.; Engesser, K. H.; Cerniglia, C. E. Evidence for the existence of PAH-quinone reductase and catechol-O-methyltransferase in Mycobacterium vanbaalenii PYR-1. J. Ind. Microbiol. Biotechnol. 2004, 31, 507-516.

(31) Kim, B. G.; Jung, B. R.; Lee, Y.; Hur, H. G.; Lim, Y.; Ahn, J. H. Regiospecific flavonoid 7-O-Methylation with Streptomyces avermitilis O-Methyltransferase expressed in Escherichia coli. J. Agric. Food Chem. 2006, 54, 823-828.

(32) Yang, H.; Ahn, J. H.; Ibrahim, R. K.; Lee, S.; Lim, Y. The threedimensional structure of Arabidopsis thaliana O-methyltransferase predicted by homology-based modelling. J. Mol. Graphics Modell. 2004, 23, 77-87.

(33) Vizioli, E. D.; Chin, C. M.; Menegon, R. F.; Blau, L.; Santos, J. L.; Longo, M. D. Compounds derived from taurine, process of their preparation and pharmaceutical compositions containing these, U.S. Patent No. 8,569,335 2013.

(34) Bischof, I.; Köster, J.; Segner, H.; Schlechtriem, C. Hepatocytes as in vitro test system to investigate metabolite patterns of pesticides in farmed rainbow trout and common carp: Comparison between in vivo and in vitro and across species. Comp. Biochem. Physiol., Part C: Toxicol. Pharmacol. 2016, 187, 62-73.

(35) OECD. OECD test guideline No.319A; OECD, 2018.

(36) Escher, B. I.; Hermens, J. L. M. Modes of action in ecotoxicology: Their role in body burdens, species sensitivity, QSARs, and mixture effects. Environ. Sci. Technol. 2002, 36, 42014217.

(37) Baumer, A.; Bittermann, K.; Klüver, N.; Escher, B. I. Baseline toxicity and ion-trapping models to describe the $\mathrm{pH}$-dependence of bacterial toxicity of pharmaceuticals. Environ. Sci. Process. Impacts 2017, 19, 901-916.

(38) Klüver, N.; Bittermann, K.; Escher, B. I. QSAR for baseline toxicity and classification of specific modes of action of ionizable organic chemicals in the zebrafish embryo toxicity test. Aquat. Toxicol. 2019, 207, 110-119.

(39) Fu, Q.; Rösch, A.; Fedrizzi, D.; Vignet, C.; Hollender, J. Bioaccumulation, Biotransformation and Synergistic Effects of Binary Fungicide Mixtures in Hyalella azteca and Gammarus pulex: How Different/Similar are the Two Species? Environ. Sci. Technol. 2018, 52, 13491-13500.

(40) Schymanski, E. L.; Jeon, J.; Gulde, R.; Fenner, K.; Ruff, M.; Singer, H. P.; Hollender, J. Identifying small molecules via high resolution mass spectrometry: Communicating confidence. Environ. Sci. Technol. 2014, 48, 2097-2098.

(41) Sarda, S.; Page, C.; Pickup, K.; Schulz-Utermoehl, T.; Wilson, I. Diclofenac metabolism in the mouse: Novel in vivo metabolites identified by high performance liquid chromatography coupled to linear ion trap mass spectrometry. Xenobiotica 2012, 179.

(42) Stierlin, H.; Faigle, J. W.; Sallmann, A.; Kung, W.; Richter, W. J.; Kriemler, H.-P.; Alt, K. O.; Winkler, T. Biotransformation of diclofenac sodium (Voltaren ${ }^{\circledR}$ ) in animals and in man. Xenobiotica 1979, 9, 601-610.

(43) James, M. O. Disposition and taurine conjugation of 2,4dichlorophenoxyacetic acid, 2,4,5-trichlorophenoxyacetic acid, bis(4chlorophenyl)acetic acid, and phenylacetic acid in the spiny lobster, Panulirus argus. Drug Metab. Dispos. 1982, 10, 516-522.

(44) Barron, M. G.; Hansen, S. C.; Ball, T. Pharmacokinetics and metabolism of triclopyr in the crayfish (Procambarus clarki). Drug Metab. Dispos. 1991, 19, 163-167.

(45) Brox, S.; Seiwert, B.; Haase, N.; Küster, E.; Reemtsma, T. Metabolism of clofibric acid in zebrafish embryos (Danio rerio) as determined by liquid chromatography-high resolution-mass spectrometry. Comp. Biochem. Physiol. C Toxicol. Pharmacol. 2016, 185$186,20-28$.
(46) James, M. O.; Bend, J. R. Taurine conjugation of 2,4dichlorophenoxyacetic acid and phenylacetic acid in two marine species. Xenobiotica 1976, 6, 393-398.

(47) Dixon, P. A. F.; Caldwell, J.; Smith, R. L. Metabolism of Arylacetic Acids: 2. The Fate of [14C] Hydratropic Acid and its Variation with Species. Xenobiotica 1977, 7, 707-715.

(48) Knights, K. M.; Sykes, M. J.; Miners, J. O. Amino acid conjugation: contribution to the metabolism and toxicity of xenobiotic carboxylic acids. Expert Opin. Drug Metab. Toxicol. 2007, 3, 159-168.

(49) Kallio, J. M.; Lahti, M.; Oikari, A.; Kronberg, L. Metabolites of the aquatic pollutant diclofenac in fish bile. Environ. Sci. Technol. 2010, 44, 7213-7219.

(50) Lee, H. J.; Lee, E.; Yoon, S. H.; Chang, H. R.; Kim, K.; Kwon, J. $H$. Enzymatic and microbial transformation assays for the evaluation of the environmental fate of diclofenac and its metabolites. Chemosphere 2012, 87, 969-974.

(51) Lahti, M.; Brozinski, J. M.; Jylhä, A.; Kronberg, L.; Oikari, A. Uptake from water, biotransformation, and biliary excretion of pharmaceuticals by rainbow trout. Environ. Toxicol. Chem. 2011, 30, 1403-1411.

(52) Bonnefille, B.; Arpin-Pont, L.; Gomez, E.; Fenet, H.; Courant, F. Metabolic profiling identification of metabolites formed in Mediterranean mussels (Mytilus galloprovincialis) after diclofenac exposure. Sci. Total Environ. 2017, 583, 257-268.

(53) Stierlin, H.; Faigle, J. W.; Sallmann, A.; Kung, W.; Richter, W. J.; Kriemler, H.-P.; Alt, K. O.; Winkler, T. Biotransformation of diclofenac sodium (Voltaren ${ }^{\circledR}$ ) in animals and in man. I. Isolation and identification of principal metabolites. Xenobiotica 1979, 9, 601610.

(54) Fu, Q.; Ye, Q.; Zhang, J.; Richards, J.; Borchardt, D.; Gan, J. Diclofenac in Arabidopsis cells: Rapid formation of conjugates. Environ. Pollut. 2017, 222, 383-392.

(55) Stravs, M. A.; Pomati, F.; Hollender, J. Exploring micropollutant biotransformation in three freshwater phytoplankton species. Environ. Sci. Process. Impacts 2017, 822-832.

(56) James, M. O.; Marth, C. J.; Rowland-Faux, L. Slow Odemethylation of methyl triclosan to triclosan, which is rapidly glucuronidated and sulfonated in channel catfish liver and intestine. Aquat. Toxicol. 2012, 124-125, 72-82.

(57) Polesel, F.; Andersen, H. R.; Trapp, S.; Plósz, B. G. Removal of Antibiotics in Biological Wastewater Treatment Systems - A Critical Assessment Using the Activated Sludge Modeling Framework for Xenobiotics (ASM-X). Environ. Sci. Technol. 2016, 50, 10316-10334.

(58) Bahlmann, A.; Brack, W.; Schneider, R. J.; Krauss, M. Carbamazepine and its metabolites in wastewater: Analytical pitfalls and occurrence in Germany and Portugal. Water Res. 2014, 57, 104114.

(59) Vieno, N.; Tuhkanen, T.; Kronberg, L. Elimination of pharmaceuticals in sewage treatment plants in Finland. Water Res. 2007, 41, 1001-1012.

(60) Lam, K. C.; Ibrahim, R. K.; Behdad, B.; Dayanandan, S. Structure, function, and evolution of plant $\mathrm{O}$-methyltransferases. Genome 2007, 50, 1001-1013.

(61) Petronikolou, N.; Nair, S. K. Biochemical Studies of Mycobacterial Fatty Acid Methyltransferase: A Catalyst for the Enzymatic Production of Biodiesel. Chem. Biol. 2015, 22, 1480-1490.

(62) Siegrist, J.; Netzer, J.; Mordhorst, S.; Karst, L.; Gerhardt, S.; Einsle, O.; Richter, M.; Andexer, J. N. Functional and structural characterisation of a bacterial $\mathrm{O}$-methyltransferase and factors determining regioselectivity. FEBS Lett. 2017, 591, 312-321.

(63) Mo, X.; Gui, C.; Wang, Q. Elucidation of a carboxylate Omethyltransferase $\mathrm{NcmP}$ in nocamycin biosynthetic pathway. Bioorg. Med. Chem. Lett. 2017, 27, 4431-4435.

(64) Petrossian, T. C.; Clarke, S. G. Uncovering the Human Methyltransferasome. Mol. Cell. Proteomics 2011, 10, M110.000976.

(65) US EPA. Estimation Programs Interface Suite for Microsoft Windows, V4.11; US EPA, 2013. 